\title{
A comparison of static and dynamic cerebral autoregulation during mild whole-body cold stress in individuals with and without cervical spinal cord injury: a pilot study
}

\author{
Jan W. van der Scheer ${ }^{1,2} \cdot$ Yoshi-Ichiro Kamijo $^{3} \cdot$ Christof A. Leicht $^{1,2} \cdot$ Philip J. Millar $^{4} \cdot$ Manabu Shibasaki $^{5}$. \\ Victoria L. Goosey-Tolfrey ${ }^{1,2} \cdot$ Fumihiro Tajima $^{3}$
}

Received: 30 May 2017 / Revised: 14 September 2017 / Accepted: 14 September 2017 / Published online: 12 January 2018

(c) International Spinal Cord Society 2018

\begin{abstract}
Study design Experimental study.

Objectives To characterize static and dynamic cerebral autoregulation (CA) of individuals with cervical spinal cord injury (SCI) compared to able-bodied controls in response to moderate increases in mean arterial pressure (MAP) caused by mild whole-body cold stress.
\end{abstract}

Setting Japan

Methods Five men with complete autonomic cervical SCI (sustained $>5 \mathrm{y}$ ) and six age-matched able-bodied men participated in hemodynamic, temperature, catecholamine and respiratory measurements for $60 \mathrm{~min}$ during three consecutive stages: baseline (10 min; $33^{\circ} \mathrm{C}$ water through a thin-tubed whole-body suit), mild cold stress $\left(20 \mathrm{~min} ; 25^{\circ} \mathrm{C}\right.$ water), and post-cold recovery $\left(30 \mathrm{~min} ; 33^{\circ} \mathrm{C}\right.$ water). Static CA was determined as the ratio between mean changes in middle cerebral artery blood velocity and MAP, dynamic CA as transfer function coherence, gain, and phase between spontaneous changes in MAP to middle cerebral artery blood velocity.

Results MAP increased in both groups during cold and post-cold recovery (mean differences: 5-10 mm Hg; main effect of time: $p=0.001$ ). Static CA was not different between the able-bodied vs. the cervical SCI group (mean (95\% confidence interval (CI)) of between-group difference: -4 ( -11 to 3$)$ and -2 ( -5 to 1$) \mathrm{cm} / \mathrm{s} / \mathrm{mm} \mathrm{Hg}$ for cold $(p=0.22)$ and post-cold $(p=0.24)$, respectively). At baseline, transfer function phase was shorter in the cervical SCI group (mean $(95 \% \mathrm{CI})$ of between-group difference: 0.6 ( 0.2 to 1.0$) \mathrm{rad} ; p=0.006)$, while between-group differences in changes in phase were not different in response to the cold stress (interaction term: $p=0.06$ ).

Conclusions This pilot study suggests that static CA is similar between individuals with cervical SCI and able-bodied controls in response to moderate increases in MAP, while dynamic CA may be impaired in cervical SCI because of disturbed sympathetic control.

\footnotetext{
Jan W. van der Scheer

j.scheer@lboro.ac.uk

$\triangle$ Fumihiro Tajima

fumi@wakayama-med.ac.jp

1 Peter Harrison Centre for Disability Sport, School of Sport,

Exercise and Health Sciences, Loughborough University, Loughborough, UK

2 National Centre for Sport and Exercise Medicine, School of Sport,
}

Exercise and Health Sciences, Loughborough University, Loughborough, UK

3 Department of Rehabilitation Medicine, Wakayama Medical University, Wakayama, Wakayama Prefecture, Japan

4 Human Health and Nutritional Sciences, Guelph University, Guelph, Ontario, Canada

5 Department of Environmental Health, Nara Women's University, Nara, Japan 


\section{Introduction}

The precise regulation of cerebral blood flow (CBF) is essential in preventing unconsciousness and brain damage $[1,2]$. The capacity of the central vasculature to maintain $\mathrm{CBF}$ by adjusting cerebrovascular resistance over a range of mean arterial pressure (MAP) is referred to as cerebral autoregulation (CA) [3-5]. The physiological mechanisms responsible for $\mathrm{CA}$ are not yet clear, but include myogenic (smooth muscle responding to changes in vascular wall tension), cholinergic, and sympathetic mechanisms [3, 611]. $\mathrm{CA}$ is typically evaluated by measuring $\mathrm{CBF}$ changes in response to a steady-state change in MAP ("static" CA), or by measuring $\mathrm{CBF}$ changes in response to transient fluctuations in MAP ("dynamic" CA). Static CA has, for example, been determined by examining the mean $\mathrm{CBF}$ changes relative to MAP changes over $2 \mathrm{~min}$ in response to orthostatic stress [12,13], while dynamic CA is evaluated commonly using transfer function coherence, gain, and phase of spontaneous changes in MAP and CBF velocity $[14,15]$. Coherence reflects the linear correlation between changes in MAP and changes in CBF velocity, gain reflects the magnitude in which a given change in MAP alters CBF velocity, and phase reflects the time delay between changes in MAP to be reflected in changes in CBF velocity $[14,15]$. A higher transfer function gain can be interpreted as the primary indicator of less adequate dynamic $\mathrm{CA}$, while a higher coherence and shorter phase may also reflect less adequate dynamic CA $[14,15]$. Important to note is that static and dynamic CA represent two experimental approaches for quantifying the relationship between MAP and $\mathrm{CBF}$ velocity over different timescales [6] and not necessarily distinct physiological mechanisms [3].

Whether disruption of central sympathetic control, present in individuals with cervical spinal cord injury (SCI) [16], leads to inadequate CA remains unclear [17-19]. An inability to buffer the frequently occurring periods of high and low MAP caused by impaired sympathetic control [16] may explain why the SCI population is at increased risk of stroke and cerebrovascular disease [18, 20, 21]. Prior studies indicate that static CA is not different in participants with chronic cervical SCI compared to able-bodied controls (see ref. ${ }^{17}$ for an overview), while data from able-bodied participants indicate that pharmaceutically induced sympathetic blockade has little or no effect on static CA [6, 22]. However, each of these studies tested the capacity to maintain $\mathrm{CBF}$ during reductions in MAP, which in ablebodied individuals exhibits less effective buffering than increases in MAP, a phenomenon called CA hysteresis [3, $4,23,24]$. Static CA has also been reported to be similar between participants with SCI and able-bodied controls in response to increases in MAP evoked via the cold pressor test $[25,26]$. However, it remains unclear whether this stress elicited peripherally mediated sympathetic outflow secondary to autonomic dysreflexia [27-29]. Furthermore, prior studies have largely failed to measure respiratory rate, $\mathrm{PaO}_{2}$ and $\mathrm{PaCO}_{2}$, which can influence interpretation of $\mathrm{CA}$ $[15,30,31]$. As such, it is yet to be tested whether static CA is also similar between individuals with cervical SCI and able-bodied controls in response to moderate increases in MAP without peripherally mediated sympathetic outflow and changes in respiratory rate, $\mathrm{PaO}_{2}$ and $\mathrm{PaCO}_{2}$.

The effects of cervical SCI and the role of disturbed sympathetic control of the cerebrovasculature on dynamic CA are also unclear. A recent study reported that participants with SCI at or above the 4th thoracic segment had a shorter transfer function phase compared to able-bodied controls during supine conditions, suggesting that dynamic $\mathrm{CA}$ is impaired in cervical SCI [32]. Earlier studies also demonstrated a higher transfer function gain or shorter phase in participants with cervical SCI compared to able-bodied controls during an orthostatic challenge that decreased MAP $[19,33]$. However, transfer function coherence, gain, and phase during a stress that moderately increases MAP has never been studied in individuals with cervical SCI.

Therefore, the objective of this pilot study was to characterize static and dynamic CA of individuals with cervical SCI compared to able-bodied controls in response to a moderate increase in MAP caused by mild whole-body cold stress, in order to provide insight into the effect of disturbed central sympathetic control of the cerebrovasculature on CA. We hypothesized that in response to a moderate increase in MAP 1) static CA would be similar between the cervical SCI and able-bodied group; and 2) dynamic CA, operationalized by transfer function coherence, gain and phase, would be different between the cervical SCI and able-bodied group.

\section{Materials and methods}

\section{Participants}

Five otherwise healthy men with C5/C6 lesions (5-26 y post injury; American Spinal Injury Association Impairment Scale (AIS) A: $n=4$; AIS B: $n=1$ ) participated in the study, along with six healthy age-matched able-bodied men who served as a control group (Table 1). Resting levels of plasma noradrenaline $<94 \mathrm{pg} / \mathrm{mL}$ indicated autonomic completeness [19, 34] (Table 1). In addition, the drop of $19-30 \mathrm{~mm} \mathrm{Hg}$ in systolic blood pressure measured during a sit-up test [35] was also suggestive of autonomic completeness. Two additional participants (SCI: $n=1$, aged $25 \mathrm{y}$; able-bodied: $n=1$, aged $28 \mathrm{y}$ ) were excluded from the study, given an unanticipated decrease in MAP during the cold stress stage (SCI: $-7 \mathrm{~mm}$ $\mathrm{Hg}$; able-bodied: $-11 \mathrm{~mm} \mathrm{Hg}$ ). 
Table 1 Baseline participant characteristics in the able-bodied compared to the cervical spinal cord injury group

\begin{tabular}{|c|c|c|c|}
\hline & $\begin{array}{l}\text { Able-bodied } \\
(n=6)\end{array}$ & $\begin{array}{l}\text { Cervical SCI } \\
(n=5)\end{array}$ & $\begin{array}{l}\text { Able-bodied vs. } \\
\text { cervical SCI }\end{array}$ \\
\hline & Mean \pm SD & Mean \pm SD & $\begin{array}{l}\text { Mean }(95 \% \mathrm{CI}) \\
\text { difference }\end{array}$ \\
\hline \multicolumn{4}{|l|}{ Demographics/anthropometrics } \\
\hline Age $(y)$ & $40 \pm 15$ & $36 \pm 9$ & $4(-13$ to 21$)$ \\
\hline Height (m) & $174 \pm 6$ & $178 \pm 9$ & $-5(-15$ to 5$)$ \\
\hline Body weight (kg) & $67 \pm 6$ & $63 \pm 15$ & $4(-12$ to 19$)$ \\
\hline \multicolumn{4}{|l|}{ Hemodynamic } \\
\hline MAP $(\mathrm{mm} \mathrm{Hg})$ & $85 \pm 8$ & $79 \pm 9$ & $6(-6$ to 17$)$ \\
\hline $\mathrm{CBF}$ velocity $(\mathrm{cm} / \mathrm{s})$ & $63 \pm 12$ & $67 \pm 20$ & $-4(-25$ to 18$)$ \\
\hline Heart rate $(\mathrm{b} / \mathrm{min})$ & $70 \pm 11$ & $56 \pm 6$ & 15 (2 to 27$)^{*}$ \\
\hline Stroke volume $(\mathrm{mL})$ & $77 \pm 8$ & $77 \pm 17$ & $0(-17$ to 17$)$ \\
\hline Cardiac output (L/min) & $5.5 \pm 1.0$ & $4.6 \pm 1.3$ & $0.9(-0.6$ to 2.5$)$ \\
\hline \multicolumn{4}{|l|}{ Body temperature } \\
\hline Mean skin temperature $\left({ }^{\circ} \mathrm{C}\right)$ & $34.9 \pm 0.6$ & $34.6 \pm 0.6$ & $0.3(-0.5$ to 1.1$)$ \\
\hline Oesophageal temperature $\left({ }^{\circ} \mathrm{C}\right)$ & $36.7 \pm 0.2$ & $36.7 \pm 0.6$ & $0.0(-0.6$ to 0.5$)$ \\
\hline \multicolumn{4}{|l|}{ Respiratory } \\
\hline End-tidal $\mathrm{P}_{\mathrm{CO} 2}(\mathrm{~mm} \mathrm{Hg})$ & $39 \pm 3$ & $38 \pm 2$ & $-2(-2$ to 6$)$ \\
\hline End-tidal $\mathrm{P}_{\mathrm{O} 2}(\mathrm{~mm} \mathrm{Hg})$ & $106 \pm 2$ & $109 \pm 5$ & $-3(-8$ to 2$)$ \\
\hline Respiratory rate $(\mathrm{Hz})$ & $0.25 \pm 0.07$ & $0.27 \pm 0.09$ & $-0.02(-0.13$ to 0.09$)$ \\
\hline \multicolumn{4}{|l|}{ Catecholamines } \\
\hline Noradrenaline & $228 \pm 80$ & $56 \pm 30$ & $172(85 \text { to } 258)^{* *}$ \\
\hline Adrenaline & $37 \pm 11$ & $7 \pm 4$ & $30(18 \text { to } 42)^{* * *}$ \\
\hline \multicolumn{4}{|l|}{ Spectral power } \\
\hline Power MAP $\left(\mathrm{mm} \mathrm{Hg}^{2} / \mathrm{Hz}\right)$ & $21 \pm 20$ & $2 \pm 1$ & $-18(-1$ to -34$)$ \\
\hline Power CBF velocity $\left([\mathrm{cm} / \mathrm{sec}]^{2} / \mathrm{Hz}\right)^{\mathrm{a}}$ & $17 \pm 27$ & $10 \pm 13$ & $-7(-31$ to 18$)$ \\
\hline
\end{tabular}

$\mathrm{MAP}=$ mean arterial pressure; $\mathrm{SCI}=$ spinal cord injury; $\mathrm{CBF}=$ cerebral blood flow

$* p<0.05 ; * * p<0.01 ; * * * p<0.001$ in unpaired two-tailed Student $t$-tests

a Tested after log transform, as data were not normally distributed

\section{Procedures}

All participants fasted for $\geq 4 \mathrm{~h}$ before the trial and emptied their bladder upon arrival at the testing facilities. Participants were tested in a supine position wearing a thin-tubed whole-body suit (Allen-Vanguard Technologies Inc., Ottawa, ON, Canada) in a laboratory with an ambient temperature of $27.5-28.6{ }^{\circ} \mathrm{C}$ and $40-45 \%$ relative humidity. The water-perfused suit covered the entire skin surface except for the feet, hands, and head [36]. Standardized whole-body normothermic conditions at the start of trial were achieved by perfusing $33{ }^{\circ} \mathrm{C}$ water through the suit for $\sim 30$ min during instrumentation [36]. After this, the total time of the trial was $60 \mathrm{~min}$, consisting of three consecutive stages: baseline normothermic conditions (10 min with $33^{\circ} \mathrm{C}$ water through the suit), mild cold stress ( $20 \mathrm{~min}$ with $25^{\circ} \mathrm{C}$ water), and post-cold recovery (30 min with $33{ }^{\circ} \mathrm{C}$ water). Previous data indicated that $20 \mathrm{~min}$ of cold is the minimal duration to evoke a drop in skin temperature and that $30 \mathrm{~min}$ is the minimum duration required to return skin temperature to normothermic levels [36]. The use of previously established minimum durations was also used to reduce the risk of pressure sores. To further reduce the risk of pressure sores, participants with cervical SCI were manually lifted from the table for $1 \mathrm{~min}$ after each of the instrumentation, baseline, and cold stress stages. Hemodynamic, body temperature, and respiratory measurements were conducted continuously throughout the trial, while blood samples for catecholamines were taken $3 \mathrm{~min}$ before the end of each stage.

\section{Hemodynamic outcomes}

Discrete systolic and diastolic blood pressures were measured each minute using an upper-arm cuff on the right arm (Tango ${ }^{+}$, SunTech Medical Inc., Morrisville, NC, USA). MAP was calculated by: diastolic blood pressure plus onethird multiplied by pulse pressure [37]. CBF velocity was measured in the middle carotid artery at $200 \mathrm{~Hz}$ using a 2$\mathrm{MHz}$ probe (WAKI, Atys Médical, Soucieu-en-Jarrest, France) placed over the participant's temporal window. The probe was fixed at a constant angle with a custom-made probe holder. The transcranial Doppler ultrasound sample volume was adjusted to capture the proximal segment of the middle carotid artery, after which an optimal signal was obtained by trying different angles and positions of the probe [22]. Beat-by-beat blood pressure was measured at $200 \mathrm{~Hz}$ using finger photoplethysmography (MUB101-50, MediSense Inc., Tokyo, Japan) from a long or ring finger digit on the left hand. Heart rate was determined using the peak-to-peak intervals of the beat-by-beat blood pressure signal. Impedance cardiography was used to measure stroke volume and cardiac output at a sample frequency of $1 \mathrm{~Hz}$ (PhysioFlow Lab-1, Manatec Biomedical, Paris, France).

\section{Body temperature}

Esophageal temperature was measured at a sample frequency of $2 \mathrm{~Hz}$ using a copper-constantan thermocouple (LT6A, Gram Corporation, Saitama, Japan) [36]. Skin temperature was collected using a similar sensor at seven sites: forehead, chest, abdomen, upper arm, lower arm, thigh, and calf [36]. Mean skin temperature was calculated based on weighting of each site: forehead (0.07), chest (0.175), abdomen (0.175), upper arm (0.1), lower arm (0.1), thigh (0.2), and calf (0.16) [38].

\section{Respiratory outcomes}

Open-circuit spirometry and mass spectrometry (ARCO-2000, Arco System Inc., Kashiwa, Japan) were used to measure respiratory rate, $P_{\mathrm{ETCO} 2}$, and $\mathrm{P}_{\mathrm{ETO} 2}$, which have been shown to be valid estimators of $P_{\mathrm{aO} 2}$ and $P_{\mathrm{aCO} 2}$ [30]. 


\section{Catecholamines}

Blood samples were analyzed for noradrenaline and adrenaline plasma concentrations using high-performance liquid chromatography (coefficients of variation computed by analysis of standards: $8.8 \%$ and $7.0 \%$, respectively).

\section{Data analysis}

Data processing was conducted using Matlab 2015b (Mathworks, Natick, MA, USA). Data over the last 5 min of each condition were selected for further analyses. A different time window with steady-state body temperature was selected if CBF data contained artifacts [39]. Only 4 or 4.5 min of artifact-free CBF velocity data was available in some participants (baseline: $n=2$; cold: $n=1$; post-cold: $n=1$ ), but this was still considered sufficient [40]. The mean over the selected window was calculated for all outcomes.

\section{Static and dynamic CA}

Static CA was determined as the ratio between mean changes in CBF velocity and MAP $(\mathrm{cm} / \mathrm{s} / \mathrm{mm} \mathrm{Hg})$ [4] from baseline to the mild cold stress, and from baseline to the post-cold recovery. For the spectral power and transfer function outcomes underpinning dynamic CA, beat-to-beat MAP and CBF velocity were obtained by integrating the respective signals within each cardiac cycle. Cardiac cycles were determined based on the diastolic (nadir-to-nadir) intervals of the beat-by-beat blood pressure signal. Beat-tobeat MAP and CBF velocity were first linearly interpolated and resampled at $2 \mathrm{~Hz}$ and then detrended by subtracting their 3rd order polynomial [15, 22]. Subsequently, the beatto-beat time series were used for spectral and transfer function analyses based on the Welch algorithm [15]. Each time series was subdivided into successive 256-point Hann windows that overlapped by $50 \%$ before fast Fourier transform analysis $[14,15]$. This resulted in a spectral resolution of $0.0020 \mathrm{~Hz}$ in all but two participants $(0.0039$ $\mathrm{Hz}$ ). The cross-spectrum between MAP (input) and CBF velocity (output) was determined and divided by the MAP autospectrum to derive the transfer function coherence, gain, and phase [15]. Spectral power of MAP and CBF velocity as well as coherence, gain, and phase were averaged over the previously established $0.07-0.20 \mathrm{~Hz}$ lowfrequency bandwidth [15], which is considered to be the primary bandwidth representing sympathetic influences on the vasculature [41]. The contribution of gain and phase toward the band average was weighted according to their individual precision, which depended on coherence at each spectral frequency [14].

\section{Statistical analyses}

A previous study found significant differences between an able-bodied $(n=7)$ vs. a cervical SCI group $(n=4)$ in transfer function gain during supine conditions $(1.1 \pm 0.1$ vs. $1.5 \pm 0.1 \mathrm{~mm} / \mathrm{s} / \mathrm{mm} \mathrm{Hg}$, respectively) [19]. These data were used in $G^{*}$ Power 3.1.9.3 for Mac OS $X$ [42] to estimate that sample sizes of $N \geq 5$ (able-bodied) and $N \geq 3$ (cervical SCI), based on $95 \%$ power, are required to detect mean differences in transfer function gain of $0.4 \mathrm{~cm} / \mathrm{s} / \mathrm{mm} \mathrm{Hg}$, using a two-tailed test with $\alpha=0.05$. The mean and $95 \%$ confidence interval (CI) of the difference was calculated for each within and betweengroup comparison. In addition, parametric statistics were applied to all outcome measures with a normal distribution, which was assessed using Shapiro-Wilks tests $(p<0.05)$. Data were log-transformed if the Shapiro-Wilk test indicated a non-normal distribution. Comparison of baseline characteristics between the able-bodied and cervical SCI group were conducted using unpaired twotailed Student's $t$-tests. Hemodynamic, body temperature, respiratory, and catecholamine responses from baseline to mild cold stress and post-cold recovery within and between the able-bodied and cervical SCI group were assessed using $2 \times 3$ repeated measures ANOVA. Between-group comparisons of static and dynamic CA outcomes were conducted using unpaired two-tailed Student's $t$-tests. The interaction term of $2 \times 3$ ANOVA was used to assess whether responses in transfer function coherence, gain, and phase to mild cold stress and post-cold recovery were different between the able-bodied and cervical SCI group. The significance level was set at $p<0.05$. Analyses were conducted using SPSS Statistics v22 (SPSS Inc., Chicago, CA, USA).

\section{Statement of ethics}

The authors certify that all applicable institutional and governmental regulations concerning the ethical use of human volunteers were followed during the course of this research.

\section{Results}

\section{Baseline characteristics}

Table 1 presents all between-group comparisons of baseline characteristics. Lower heart rate $(p=0.03)$, noradrenaline $(p=0.001)$, and adrenaline $(p<0.001)$ outcomes were found in the cervical SCI compared to the able-bodied group. No between-group differences were observed in the other hemodynamic $(p=0.20-0.99)$, body 
temperature $(p=0.37-0.98)$, respiratory $(p=0.19-0.66)$, and spectral power outcomes $(p=0.07-0.61)$ at baseline.

\section{Responses to mild whole-body cold stress}

Table 2 presents all within-group responses during and following exposure to the mild cold stress. Hemodynamic responses were similar in both groups (interaction terms: $p=0.12-0.91$ ). An increase in MAP was found in the groups from baseline to cold and post-cold (main effect of time: $p=0.001)$. Heart rate decreased in both groups from baseline to cold (main effect of time: $p=0.02$ ), leading to a decrease in cardiac output (main effect of time: $p=0.02$ ). Body temperature responses were also similar in both groups (interaction terms: $p=0.21-0.27$ ). Mean skin temperature decreased during the cold stage (main effect of time: $p<0.001)$ and returned to baseline levels during the post-cold stage. Esophageal temperature was stable from baseline to cold, but decreased during the post-cold stage (main effect of time: $p<0.001$ ). Respiratory outcomes were stable in both groups (main effects of time: $p=0.57-0.97$; interaction terms: $p=0.33-0.91$ ), indicating that these outcomes did not confound the interpretation of static or dynamic CA results (see below). For catecholamines, the increases in noradrenaline in the able-bodied group during cold and post-cold recovery differed from the stable noradrenaline levels observed in the cervical SCI group (main effect of time: $p<0.001$; interaction term: $p<0.001$ ), in contrast to the responses observed in adrenaline (main effect of time: $p=0.06$; interaction term: $p=0.09$ ). In the spectral outcomes, no differences were observed in the groups for low-frequency power of MAP or CBF velocity (main effect of time: $p=0.15$ and 0.80 ; interaction terms: $p=0.10$ and 0.15 , respectively).

\section{Static CA}

In both groups, only small or no changes in CBF velocity were observed during and following exposure to the mild cold stress when faced with the increases in MAP (Table 2). As such, no differences in static CA were observed for the cold stress when the able-bodied group (mean $\pm \mathrm{SD}$ : $0 \pm 2 \mathrm{~cm} / \mathrm{s} / \mathrm{mm} \mathrm{Hg}$ ) and cervical SCI group (mean \pm SD: $4 \pm 8 \mathrm{~cm} / \mathrm{s} / \mathrm{mm} \mathrm{Hg}$ ) were compared (mean $(95 \% \mathrm{CI})$ of between-group difference: -4 $(-11$ to 3$) \mathrm{cm} / \mathrm{s} / \mathrm{mm} \mathrm{Hg} ; \quad p=0.24)$. Also, for the post-cold recovery, no differences in static CA were observed when the able-bodied group (mean $\pm \mathrm{SD}$ : $0 \pm 1 \mathrm{~cm} / \mathrm{s} / \mathrm{mm} \mathrm{Hg}$ ) and cervical SCI group (mean $\pm \mathrm{SD}$ : $2 \pm 3 \mathrm{~cm} / \mathrm{s} / \mathrm{mm} \mathrm{Hg}$ ) were compared (mean $(95 \% \mathrm{CI})$ of between-group difference: -2 ( -5 to 1 ) $\mathrm{cm} / \mathrm{s} / \mathrm{mm} \mathrm{Hg}$; $p=0.22$ ).

\section{Dynamic CA}

Table 3 presents the between-group comparisons of transfer function outcomes at baseline. For dynamic CA at baseline, transfer function in the cervical SCI group demonstrated a shorter phase $(p=0.006)$ but no difference in coherence ( $p$ $=0.40)$ or gain $(p=0.08)$ when compared to the ablebodied group. Figure 1 presents the responses in transfer function outcomes during and following exposure to the mild cold stress. When compared to baseline, smaller or no between-group differences in phase were observed during cold (mean $(95 \% \mathrm{CI})$ : $0.4(0.0-0.7) \mathrm{rad} ; p=0.04)$ and post-cold recovery (mean $(95 \% \mathrm{CI}): 0.2(-0.1$ to 0.5$)$ $\mathrm{rad} ; p=0.15)$. However, the responses in phase were not different between the groups when analyzed using $2 \times 3$ ANOVA (interaction term: $p=0.06$ ). Responses between the groups were also not different for coherence (interaction term: $p=0.07$ ) or gain (interaction term: $p=0.41$ ).

\section{Discussion}

This pilot study is the first to characterize static and dynamic CA in individuals with cervical SCI using a moderate increase in MAP caused by mild whole-body cold stress. Importantly, this intervention evoked a moderate increase in MAP without signs of peripherally mediated sympathetic outflow or changes in respiratory rate, $P_{\mathrm{aO} 2}$ and $P_{\mathrm{aCO} 2}$. These preliminary data suggest that static CA in response to moderate increases in MAP was similar between the cervical SCI and able-bodied group. In contrast, the shorter transfer function phase between spontaneous changes in CBF velocity and MAP in the cervical SCI group suggests that dynamic CA was impaired in the cervical SCI group. Furthermore, smaller between-group differences in transfer function phase were observed when MAP was increased in response to the mild cold stress.

The findings on static CA in response to an increase in MAP are similar to other studies that showed adequate static CA in individuals with chronic cervical SCI compared to able-bodied controls using an orthostatic challenge to decrease MAP (see ref. ${ }^{17}$ for an overview). Comparable measures of static CA were also observed in SCI and ablebodied individuals during cold pressor tests and periods of autonomic dysreflexia [25, 26, 29]. Our pilot data extend those findings by showing similar static CA during moderate MAP increases without signs of peripherally mediated increases in sympathetic outflow or changes in respiratory rate, $P_{\mathrm{aO} 2}$ and $P_{\mathrm{aCO} 2}$. Taken together, these results suggest that central sympathetic control is not a prerequisite for static CA, in line with findings of the largely unaffected static CA after pharmaceutically induced sympathetic blockade in able-bodied participants [6, 22]. 
Table 2 Within-group responses in hemodynamic, body temperature, respiratory, catecholamine, and spectral outcomes during and following exposure to mild whole-body cold stress

\begin{tabular}{|c|c|c|c|c|}
\hline & \multicolumn{2}{|l|}{ Able-bodied $(n=6)$} & \multicolumn{2}{|l|}{ Cervical SCI $(n=5)$} \\
\hline & $\begin{array}{l}\Delta \text { Baseline to cold } \\
\text { Mean } \pm \text { SD }(95 \% \mathrm{CI})\end{array}$ & $\begin{array}{l}\Delta \text { Baseline to post-cold } \\
\text { Mean } \pm \text { SD }(95 \% \mathrm{CI})\end{array}$ & $\begin{array}{l}\Delta \text { Baseline to cold } \\
\text { Mean } \pm \text { SD }(95 \% \mathrm{CI})\end{array}$ & $\begin{array}{l}\Delta \text { Baseline to post-cold } \\
\text { Mean } \pm \text { SD }(95 \% \mathrm{CI})\end{array}$ \\
\hline \multicolumn{5}{|l|}{ Hemodynamic } \\
\hline MAP upper-arm cuff $(\mathrm{mm} \mathrm{Hg})^{* *}$ & $5 \pm 3(2$ to 7$)$ & $6 \pm 4(2$ to 9$)$ & $7 \pm 7(-2$ to 16$)$ & $10 \pm 8(1$ to 20$)$ \\
\hline CBF velocity $(\mathrm{cm} / \mathrm{s})$ & $1 \pm 6(-6$ to 7$)$ & $1 \pm 5(-5$ to 7$)$ & $1 \pm 7(-7$ to 10$)$ & $2 \pm 2(0$ to 5$)$ \\
\hline Heart rate (beats/min)* & $-3 \pm 3(-6$ to 0$)$ & $0 \pm 3(-3$ to 4$)$ & $-1 \pm 1(-3$ to 0$)$ & $0 \pm 3(-4$ to 4$)$ \\
\hline Stroke volume $(\mathrm{mL})$ & $0 \pm 3(-3$ to 3$)$ & $0 \pm 5(-4 \text { to } 4)^{\mathrm{a}}$ & $1 \pm 3(-3$ to 4$)$ & $-3 \pm 7(0$ to -6$)$ \\
\hline Cardiac output $(\mathrm{L} / \mathrm{min})^{*}$ & $-0.4 \pm 0.3(-0.7$ to 0.0$)$ & $-0.1 \pm 0.3(-0.5 \text { to } 0.2)^{\mathrm{a}}$ & $-0.2 \pm 0.2(-0.4$ to 0.1$)$ & $-0.4 \pm 0.4(-0.1$ to -0.7$)$ \\
\hline \multicolumn{5}{|l|}{ Body temperature } \\
\hline Mean skin temperature $\left({ }^{\circ} \mathrm{C}\right)^{* * *}$ & $-1.7 \pm 0.5(-2.2$ to -1.2$)$ & $-0.4 \pm 0.6(-1.1$ to 0.2$)$ & $-2.1 \pm 0.3(-2.5$ to -1.7$)$ & $-0.4 \pm 0.6(-1.1$ to 0.4$)$ \\
\hline Oesophageal temperature $\left({ }^{\circ} \mathrm{C}\right)^{* * * *}$ & $0.0 \pm 0.1(-0.1$ to 0.1$)$ & $-0.2 \pm 0.1(-0.3$ to 0.0$)$ & $-0.1 \pm 0.1(-0.2$ to 0.0$)$ & $-0.3 \pm 0.2(-0.5$ to -0.1$)$ \\
\hline \multicolumn{5}{|l|}{ Respiratory } \\
\hline End-tidal $\mathrm{P}_{\mathrm{CO} 2}(\mathrm{~mm} \mathrm{Hg})$ & $1 \pm 1(0$ to 2$)$ & $0 \pm 1(-1$ to 0$)$ & $0 \pm 2(-3$ to 2$)$ & $0 \pm 0(-2$ to 1$)$ \\
\hline End-tidal $\mathrm{P}_{\mathrm{O} 2}(\mathrm{~mm} \mathrm{Hg})$ & $0 \pm 2(-2$ to 2$)$ & $0 \pm 2(-2$ to 2$)$ & $0 \pm 5(-5$ to 6$)$ & $0 \pm 3(-4$ to 3$)$ \\
\hline Respiratory rate $(\mathrm{Hz})$ & $0.01 \pm 0.04(-0.03$ to 0.05$)$ & $0.02 \pm 0.03(-0.02$ to 0.05$)$ & $0.00 \pm 0.02(-0.03$ to 0.03$)$ & $-0.01 \pm 0.03(-0.05$ to 0.03$)$ \\
\hline \multicolumn{5}{|l|}{ Catecholamines } \\
\hline Noradrenaline ${ }^{* * * \#}$ & $47 \pm 81(-38$ to 133$)$ & $183 \pm 72(108$ to 258$)$ & $-1 \pm 21(-27$ to 25$)$ & $21 \pm 17(-1$ to 43$)$ \\
\hline Adrenaline & $-5 \pm 9(-14$ to 4$)$ & $13 \pm 22(-10$ to 36$)$ & $0 \pm 0(0$ to 0$)$ & $1 \pm 2(-1$ to 3$)$ \\
\hline \multicolumn{5}{|l|}{ Spectral power } \\
\hline Power MAP $\left(\mathrm{mm} \mathrm{Hg}^{2} / \mathrm{Hz}\right)$ & $6.2 \pm 8.4(-2.6$ to 15.1$)$ & $1.4 \pm 3.6(-2.5$ to 5.2$)$ & $0.0 \pm 1.0(-1.2$ to 1.3$)$ & $1.2 \pm 1.0(-0.1$ to 2.4$)$ \\
\hline Power CBF velocity $\left([\mathrm{cm} / \mathrm{sec}]^{2} / \mathrm{Hz}\right)^{\mathrm{b}}$ & $0.7 \pm 5.8(-5.3$ to 6.8$)$ & $-2.3 \pm 10.0(-12.8$ to 8.2$)$ & $1.1 \pm 3.0(-2.6$ to 4.8$)$ & $4.7 \pm 4.4(-0.8$ to 10.2$)$ \\
\hline
\end{tabular}

$\mathrm{MAP}=$ mean arterial pressure; $\mathrm{SCI}=$ spinal cord injury; $\mathrm{CBF}=$ cerebral blood flow; $\Delta$ Baseline to cold $=$ cold - baseline; $\Delta$ Baseline to postcold $=$ post-cold - baseline

$* p<0.05 ; * * p<0.01 ; * * p<0.001$ for main effect of time in $2 \times 3$ repeated measures ANOVA

$\# p<0.001$ for the interaction term in $2 \times 3$ repeated measures ANOVA

${ }^{a}$ Missing data for $n=1$

b Tested after log transform, as data were not normally distributed

In contrast to static $\mathrm{CA}$, differences between the cervical $\mathrm{SCI}$ and able-bodied group were found in transfer function phase based on spontaneous changes in MAP and CBF velocity during normothermic supine baseline conditions, suggesting that sympathetic control is required for optimal dynamic CA [6]. The focus on static CA in older studies could explain why it was traditionally thought that sympathetic mechanisms had no role in CA [6, 9, 11, 43]. A shortened transfer function phase in participants with cervical SCI compared to able-bodied controls, along with an absence of differences in transfer function coherence and gain, was also found in a recent, larger study during supine baseline conditions [32]. The mean between-group difference in phase in that study of $0.2 \mathrm{rad}(95 \% \mathrm{CI}$ of the difference not reported) was somewhat smaller than the mean of $0.6 \mathrm{rad}(95 \% \mathrm{CI}: 0.2-1.0)$ in our study. This size difference may be attributed to the inclusion in the prior study of participants with lesions at or the 4th thoracic segment [32], who may have had more sympathetic control than the participants with cervical SCI included in our study [16]. Our findings are strengthened by rigorous artifact checking [39], and the use of weighting based on coherence level when averaging phase and gain over a spectral frequency bandwidth [14]. This method is considered to minimize risk of bias inherent to low coherence [14]. Not using this method might explain why previous studies found no significant differences in phase between able-bodied and cervical SCI groups during supine conditions [19, 33, 44]. Taken together, the shortened transfer function phase found in the recent larger study [32], along with ours, suggests that intact central sympathetic control is a prerequisite for optimal dynamic $\mathrm{CA}$, providing insights that can inform the ongoing debate about the role of sympathetic control for CA $[3,9,11]$.

Besides disturbed central sympathetic control, another explanation for suboptimal CA could be the low resting blood pressure commonly occurring in individuals with cervical SCI [16, 32]. Recent data indicate that CA of healthy, able-bodied men is better adapted to compensate for transient hypertension than transient hypotension [3, 4, $23,24]$. It could be that human CA is also less effective at compensating for chronic hypotension than chronic hypertension due to reduced cerebral perfusion pressure caused by lower resting blood pressure [32]. A role of low resting blood pressures influencing dynamic CA in cervical SCI may also explain the smaller between-group difference in transfer function phase observed during the moderate increase in MAP caused by the mild cold stress, although 
Table 3 Baseline transfer function outcomes of dynamic able-bodied compared to the cervical spinal cord injury group cerebral autoregulation in the

\begin{tabular}{llll}
\hline & $\begin{array}{l}\text { Able-bodied } \\
(n=6) ; \\
\text { mean } \pm \mathrm{SD}\end{array}$ & $\begin{array}{l}\text { Cervical SCI } \\
(n=5) ; \\
\text { mean } \pm \mathrm{SD}\end{array}$ & $\begin{array}{l}\text { Able-bodied vs. } \\
\text { cervical SCI; } \\
\text { mean }(95 \% \mathrm{CI}) \text { difference }\end{array}$ \\
\hline Coherence (index of 0-1) & $0.63 \pm 0.08$ & $0.68 \pm 0.09$ & $-0.05(-0.16$ to 0.07$)$ \\
Gain $(\mathrm{cm} / \mathrm{s} / \mathrm{mm} \mathrm{Hg})$ & $0.8 \pm 0.3$ & $1.7 \pm 1.1$ & $-0.9(-1.9$ to 0.1$)$ \\
Phase $(\mathrm{rad})$ & $0.6 \pm 0.3$ & $0.0 \pm 0.3$ & $0.6(0.2-1.0)^{* *}$ \\
\hline
\end{tabular}

$S C I$ spinal cord injury

$* * p<0.01$

this remains speculative, given that responses in dynamic CA were not significantly different between the groups (Fig. 1). A longer phase could imply that the cerebrovasculature has more time to respond to transient changes in MAP using mechanisms other than sympathetic control, such as myogenic factors $[3,6,7]$.

Given the absence of signs of peripherally mediated sympathetic outflow or changes in respiratory rate, $P_{\mathrm{aO} 2}$ and $P_{\mathrm{aCO} 2}$, mild whole-body mild cold stress seems an appropriate intervention for studying the role of the disturbed central sympathetic control in cervical SCI. Not anticipated was that MAP was still significantly increased in both groups during the post-cold stage. Even though mean skin temperature returned to baseline levels during the post-cold stage, MAP was still significantly increased in the cervical SCI as well as the able-bodied group. It seems the stressor was sufficient to maintain MAP at levels similar to the cold stage, even $30 \mathrm{~min}$ after cessation of the stressor.

\section{Study limitations}

The assumption of indexing CBF using transcranial Doppler ultrasound is that the cross-sectional diameter of the insonated vessel is unchanged; CBF velocity is then proportional to CBF [3]. Although this assumption can be violated [45], various studies have shown that changes in middle cerebral artery diameter are unlikely during resting conditions without extreme changes in MAP [46]. The moderate changes in MAP independent of a change in respiratory outcomes observed in our study further strengthen the likelihood against a change in vessel diameter. The goal of the present study was to compare each participant against their own normothermic baseline. However, in this design, we cannot exclude the possibility that the observed changes in the cervical SCI group were influenced by normal variations over time or measurement error. These risks were reduced in our study by the postcold measurements demonstrating a return to baseline values in most outcomes, along with the previously reported reliability of dynamic CA metrics during supine conditions $[47,48]$, which was further enhanced by the use of rigorous artifact checking [39] and use of weighting based on
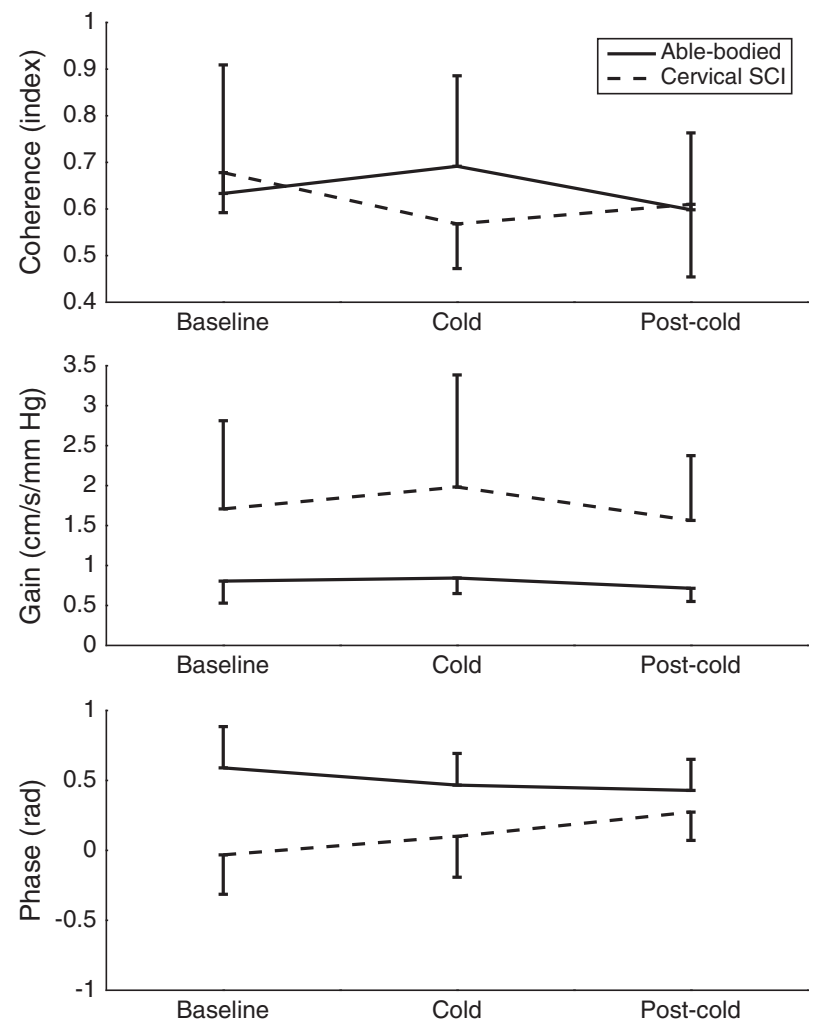

Fig. 1 Mean and SD of transfer function coherence, gain, and phase at baseline during and following exposure to mild whole-body cold stress in the cervical SCI $(n=5)$ and able-bodied group $(n=6)$. P-values represent the interaction terms of $2 \times 3$ repeated measures ANOVA

coherence level [14]. Finally, unconscious bias due to the unblind nature of the present protocol cannot be excluded. To reduce such risk, all data analyses were conducted by one author (J.W.v.d.S.) and independently verified by another author (Y.K.).

\section{Recommendations for future research}

Our data suggest the need for better understanding if and how inadequate dynamic $\mathrm{CA}$ is influencing the increased risk of stroke and other cerebrovascular conditions of 
individuals with CSCI [18, 20, 21]. Longitudinal studies are needed to understand whether and what adaptations in static and dynamic CA $[13,17]$ occur from the acute to chronic post-injury stages. Mild whole-body mild cold stress seems an appropriate intervention for further studying the role of the disturbed central sympathetic control in cervical SCI. An intervention with a longer post-cold recovery could provide further insight into the responses of CA outcomes when MAP returns to baseline after mild cold stress. Measurement of the posterior carotid artery, in addition the middle carotid artery, may elucidate if these vessels respond differently to increases in MAP caused by mild cold stress $[30,33]$. Future research on quantification of dynamic CA in individuals with cervical SCI should ideally be expanded to nonlinear relationships in addition to the linear relationships examined using transfer function analyses [49, 50]. Finally, individual data of this study should be used in a future meta-analysis regarding transfer function in cervical SCI compared to able-bodied groups. Not only can these research angles further elucidate the still debated role of the sympathetic nervous system as a mechanism contributing to CA in humans $[3,9,11]$, but they may also help reduce the risk of stroke and cerebrovascular disease of individuals with cervical SCI [18, 20, 21].

\section{Conclusions}

This pilot study suggests that in response to a moderate increase in MAP using mild cold stress, static CA is similar in individuals with cervical SCI compared to able-bodied controls. In contrast, our preliminary data suggest that dynamic CA may be impaired in individuals with cervical SCI compared to able-bodied controls due to disturbed central sympathetic control over the cerebrovasculature and/ or due to the indirect result of reduced cerebral perfusion pressure caused by lower resting blood pressure.

Acknowledgments We gratefully acknowledge the contributions to this study of Dr. Maureen MacDonald and Jason Au (McMaster University, Canada), as well as the medical doctors and physiotherapists of Wakayama Medical University (Japan).

Author contributions Jan W. van der Scheer: study concept and design, acquisition of data, analysis and interpretation of data, drafting the manuscript, approved the final version of the manuscript. YoshiIchiro Kamijo: study concept and design, acquisition of data, analysis and interpretation of data, critical revision of manuscript for intellectual content, approved the final version of the manuscript. Christof A. Leicht: study concept and design, analysis and interpretation of data, critical revision of manuscript for intellectual content, approved the final version of the manuscript. Philip J. Millar: analysis and interpretation of data, critical revision of manuscript for intellectual content, approved the final version of the manuscript. Manabu Shibasaki: study concept and design, acquisition of data, analysis and interpretation of data, critical revision of manuscript for intellectual content, approved the final version of the manuscript. Victoria L. Goosey-Tolfrey: study concept and design, analysis and interpretation of data, critical revision of manuscript for intellectual content, approved the final version of the manuscript. Fumihiro Tajima: Study concept and design, analysis and interpretation of data, critical revision of manuscript for intellectual content, approved the final version of the manuscript.

\section{Compliance with ethical standards}

Conflict of interest The authors declare that they have no conflict of interest.

Ethical approval The study was approved by the Medical Ethical Committee of Wakayama Medical University (Wakayama, Japan).

\section{References}

1. Van Lieshout JJ, Wieling W, Karemaker JM, Secher NH. Syncope, cerebral perfusion, and oxygenation. J Appl Physiol. 2003;94:833-48.

2. Smith BA, Clayton EW, Robertson D. Experimental arrest of cerebral blood flow in human subjects: the red wing studies revisited. Perspect Biol Med. 2011;54:121-31.

3. Willie CK, Tzeng YC, Fisher JA, Ainslie PN. Integrative regulation of human brain blood flow. J Physiol. 2014;592: 841-59.

4. Numan T, Bain AR, Hoiland RL, Smirl JD, Lewis NC, Ainslie PN. Static autoregulation in humans: a review and reanalysis. Med Eng Phys. 2014;36:1487-95.

5. Aaslid R, Lindegaard KF, Sorteberg W, Nornes H. Cerebral autoregulation dynamics in humans. Stroke. 1989;20:45-52.

6. Hamner JW, Tan CO, Lee K, Cohen MA, Taylor JA. Sympathetic control of the cerebral vasculature in humans. Stroke. 2010;41:102-9.

7. Hamner JW, Tan CO. Relative contributions of sympathetic, cholinergic, and myogenic mechanisms to cerebral autoregulation. Stroke. 2014;45:1771-7.

8. Tan CO, Hamner JW, Taylor JA. The role of myogenic mechanisms in human cerebrovascular regulation. J Physiol. 2013;591:5095-105.

9. Brassard P, Tymko MM, Ainslie PN. Sympathetic control of the brain circulation: appreciating the complexities to better understand the controversy. Auton. Neurosci. 2017.

10. ter Laan M, van Dijk JM, Elting JW, Staal MJ, Absalom AR. Sympathetic regulation of cerebral blood flow in humans: a review. Br J Anaesth. 2013;111:361-7.

11. Ainslie PN, Brassard P. Why is the neural control of cerebral autoregulation so controversial? F1000Prime Rep. 2014;6:14.

12. Panerai RB. Assessment of cerebral pressure autoregulation in humans--a review of measurement methods. Physiol Meas. 1998;19:305-38.

13. Houtman S, Serrador JM, Colier WN, Strijbos DW, Shoemaker K, Hopman MT. Changes in cerebral oxygenation and blood flow during LBNP in spinal cord-injured individuals. J Appl Physiol. 2001;91:2199-204.

14. Tzeng YC, Ainslie PN, Cooke WH, Peebles KC, Willie CK, MacRae BA, et al. Assessment of cerebral autoregulation: the quandary of quantification. Am J Physiol Heart Circ Physiol. 2012;303:H658-71.

15. Zhang R, Zuckerman JH, Giller CA, Levine BD. Transfer function analysis of dynamic cerebral autoregulation in humans. Am J Physiol. 1998;274(1 Pt 2):H233-41. 
16. Krassioukov A. Autonomic function following cervical spinal cord injury. Respir Physiol Neurobiol. 2009;169:157-64.

17. Phillips AA, Ainslie PN, Krassioukov AV, Warburton DE. Regulation of cerebral blood flow after spinal cord injury. J Neurotrauma. 2013;30:1551-63.

18. Kim DI, Tan CO. Alterations in autonomic cerebrovascular control after spinal cord injury. Auton Neurosci. 2017.

19. Sahota IS, Ravensbergen HR, McGrath MS, Claydon VE. Cerebrovascular responses to orthostatic stress after spinal cord injury. J Neurotrauma. 2012;29:2446-456.

20. Wu JC, Chen YC, Liu L, Chen TJ, Huang WC, Cheng H, et al. Increased risk of stroke after spinal cord injury: a nationwide 4year follow-up cohort study. Neurology. 2012;78:1051-7.

21. Phillips AA, Krassioukov AV. Contemporary cardiovascular concerns after spinal cord injury: mechanisms, maladaptations, and management. J Neurotrauma. 2015;32:1927-42.

22. Zhang R, Zuckerman JH, Iwasaki K, Wilson TE, Crandall CG, Levine BD. Autonomic neural control of dynamic cerebral autoregulation in humans. Circulation. 2002;106:1814-20.

23. Tzeng YC, Willie CK, Atkinson G, Lucas SJ, Wong A, Ainslie PN. Cerebrovascular regulation during transient hypotension and hypertension in humans. Hypertension. 2010;56:268-73.

24. Brassard P, Ferland-Dutil H, Smirl JD, Paquette M, Le Blanc O, Malenfant $S$, et al. Evidence for hysteresis in the cerebral pressureflow relationship in healthy men. Am J Physiol Heart Circ Physiol. 2017;312:H701-4.

25. Catz A, Bluvshtein V, Korczyn AD, Pinhas I, Gelernter I, Nissel $\mathrm{T}$, et al. Modified cold pressor test by cold application to the foot after spinal cord injury: suggestion of hemodynamic control by the spinal cord. Am J Phys Med Rehabil. 2007;86:875-82.

26. Catz A, Bluvshtein V, Pinhas I, Akselrod S, Gelernter I, Nissel T, et al. Cold pressor test in tetraplegia and paraplegia suggests an independent role of the thoracic spinal cord in the hemodynamic responses to cold. Spinal Cord. 2008;46:33-8.

27. Groothuis JT, Hopman MT. Hemodynamic responses to the cold pressor test in spinal cord-injured individuals; control of the splanchnic vascular bed is the key factor. Spinal Cord. 2009;47:95. author reply 96

28. Catz A. Reply to JT Groothuis and MTE Hopman's letter. Spinal Cord. 2008;47:96.

29. Phillips AA, Ainslie PN, Warburton DE, Krassioukov AV. Cerebral blood flow responses to autonomic dysreflexia in humans with spinal cord injury. J Neurotrauma. 2016;33:315-8.

30. Willie CK, Macleod DB, Shaw AD, Smith KJ, Tzeng YC, Eves ND, et al. Regional brain blood flow in man during acute changes in arterial blood gases. J Physiol. 2012;590: 3261-75.

31. Elting JW, Aries MJ, van der Hoeven JH, Vroomen PC, Maurits NM. Reproducibility and variability of dynamic cerebral autoregulation during passive cyclic leg raising. Med Eng Phys. 2014;36:585-91.

32. Phillips AA, Squair JR, Currie KD, Tzeng YC, Ainslie PN, Krassioukov AV, et al. 2015 ParaPan American games: autonomic function, but not physical activity, is associated with vascular-cognitive impairment in spinal cord injury. J Neurotrauma. 2017;34:1283-8.

33. Phillips AA, Krassioukov AV, Ainslie PN, Warburton DE. Perturbed and spontaneous regional cerebral blood flow responses to changes in blood pressure after high-level spinal cord injury: the effect of midodrine. J Appl Physiol 2014;116:645-53.
34. Claydon VE, Krassioukov AV. Clinical correlates of frequency analyses of cardiovascular control after spinal cord injury. Am J Physiol Heart Circ Physiol. 2008;294:H668-78.

35. West CR, Wong SC, Krassioukov AV. Autonomic cardiovascular control in Paralympic athletes with spinal cord injury. Med Sci Sports Exerc. 2014;46:60-8.

36. Kamijo Y, Lee K, Mack GW. Active cutaneous vasodilation in resting humans during mild heat stress. J Appl Physiol. 2005;98:829-37.

37. Zheng L, Sun Z, Li J, Zhang R, Zhang X, Liu S, et al. Pulse pressure and mean arterial pressure in relation to ischemic stroke among patients with uncontrolled hypertension in rural areas of China. Stroke. 2008;39:1932-7.

38. Choi JK, Miki K, Sagawa S, Shiraki K. Evaluation of mean skin temperature formulas by infrared thermography. Int $\mathrm{J}$ Biometeorol. 1997;41:68-75.

39. Meel-van den Abeelen AS, de Jong DL, Lagro J, Panerai RB, Claassen JA. How measurement artifacts affect cerebral autoregulation outcomes: a technical note on transfer function analysis. Med Eng Phys. 2016;38:490-7.

40. Deegan BM, Serrador JM, Nakagawa K, Jones E, Sorond FA, Olaighin $\mathrm{G}$, et al. The effect of blood pressure calibrations and transcranial Doppler signal loss on transfer function estimates of cerebral autoregulation. Med Eng Phys. 2011;33:553-62.

41. Parati G, Saul JP, Di Rienzo M, Mancia G. Spectral analysis of blood pressure and heart rate variability in evaluating cardiovascular regulation. A critical appraisal. Hypertension. 1995;25:1276-86.

42. Faul F, Erdfelder E, Lang AG, Buchner A. G*Power 3: a flexible statistical power analysis program for the social, behavioral, and biomedical sciences. Behav Res Methods. 2007;39:175-91.

43. Skinhoj E. The sympathetic nervous system and the regulation of cerebral blood flow in man. Stroke. 1972;3:711-6.

44. Wilson LC, Cotter JD, Fan JL, Lucas RA, Thomas KN, Ainslie $\mathrm{PN}$, et al. Cerebrovascular reactivity and dynamic autoregulation in tetraplegia. Am J Physiol Regul Integr Comp Physiol. 2010;298:R1035-42.

45. Verbree J, Bronzwaer A, van Buchem MA, Daemen M, van Lieshout JJ, van Osch M, et al. Middle cerebral artery diameter changes during rhythmic handgrip exercise in humans. J Cereb Blood Flow Metab. 2016:271678x16679419.

46. Willie CK, Colino FL, Bailey DM, Tzeng YC, Binsted G, Jones LW, et al. Utility of transcranial Doppler ultrasound for the integrative assessment of cerebrovascular function. J Neurosci Methods. 2011;196:221-37.

47. Brodie FG, Atkins ER, Robinson TG, Panerai RB. Reliability of dynamic cerebral autoregulation measurement using spontaneous fluctuations in blood pressure. Clin Sci. 2009;116:513-20.

48. McDonnell MN, Berry NM, Cutting MA, Keage HA, Buckley JD, Howe PR, et al. Transcranial Doppler ultrasound to assess cerebrovascular reactivity: reliability, reproducibility and effect of posture. PeerJ. 2013;1:e65.

49. Panerai RB. Nonstationarity of dynamic cerebral autoregulation. Med Eng Phys. 2014;36:576-84.

50. Saleem S, Teal PD, Kleijn WB, Ainslie PN, Tzeng YC. Identification of human sympathetic neurovascular control using multivariate wavelet decomposition analysis. Am J Physiol Heart Circ Physiol. 2016;311:H837-48.

51. Zhang R, Behbehani K, Levine BD. Dynamic pressure-flow relationship of the cerebral circulation during acute increase in arterial pressure. J Physiol. 2009;587(Pt 11):2567-77. 